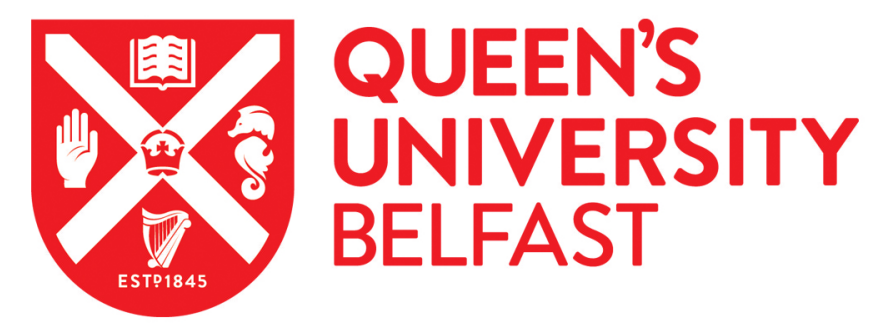

\title{
Facilitators and Barriers to Social Distancing for Young People living in Northern Ireland during the COVID-19 Pandemic
}

\author{
Berry, E., Jenkins, C., \& Allen, S. (2021). Facilitators and Barriers to Social Distancing for Young People living in \\ Northern Ireland during the COVID-19 Pandemic. https://doi.org/10.31234/osf.io/yf6hk
}

\section{Document Version:}

Early version, also known as pre-print

\section{Queen's University Belfast - Research Portal:}

Link to publication record in Queen's University Belfast Research Portal

\section{Publisher rights}

Copyright 2021 the authors.

This is an open access preprint published under a Creative Commons Attribution License (https://creativecommons.org/licenses/by/4.0/),

which permits unrestricted use, distribution and reproduction in any medium, provided the author and source are cited.

\section{General rights}

Copyright for the publications made accessible via the Queen's University Belfast Research Portal is retained by the author(s) and / or other copyright owners and it is a condition of accessing these publications that users recognise and abide by the legal requirements associated with these rights.

Take down policy

The Research Portal is Queen's institutional repository that provides access to Queen's research output. Every effort has been made to ensure that content in the Research Portal does not infringe any person's rights, or applicable UK laws. If you discover content in the Research Portal that you believe breaches copyright or violates any law, please contact openaccess@qub.ac.uk. 
1 Full title: Facilitators and Barriers to Social Distancing for Young People living in Northern Ireland

2

5 Emma Berry ${ }^{1 *}$, Chris Jenkins ${ }^{2}$, Sarah Allen ${ }^{3}$, on behalf of the HSC Research and Development

6 Division Behaviour Change Group

7

$8 \quad{ }^{1}$ School of Psychology, Queen's University Belfast, Belfast, Northern Ireland

$9 \quad{ }^{2}$ Centre for Public Health, Queen's University Belfast, Belfast, Northern Ireland

10

11

12

13

14

15

16

17

18

19

20

Main body: 5206 words (excluding tables and references)

*Corresponding author

E.Berry@qub.ac.uk

${ }^{\wedge}$ Membership of the HSC Research and Development Division Behaviour Change Group is provided in Acknowledgements.

Abstract: 241 words 


\section{Abstract}

This qualitative study explores the facilitators of and barriers to social distancing for young people living in Northern Ireland during the COVID-19 pandemic. Qualitative data was collected as part of a larger Qualtrics survey between July $28^{\text {th }} 2020$ and August $24^{\text {th }} 2020$. Eligible participants were young people living on the Island of Ireland, aged 16-25 years. The survey design was underpinned by the COM-B model of behaviour change. Semi-inductive thematic analysis was used to analyse comments collected via three free-text survey items. The COM-B model provided a thematic framework to organize subthemes extracted. A total of $\mathrm{N}=477$ young people completed the survey, of which $\mathrm{N}=352$ provided comments for at least one of three free-text survey items. The majority of respondents lived in Northern Ireland (96\%), the average age was 21 years, and most respondents were female (73\%) and were students (81\%). Key barriers identified included Social Opportunity (other people not social distancing), Physical Opportunity (lack of environmental support for social distancing), and Automatic motivation (missing physical interaction from others). Key facilitators included Physical Opportunity (environmental cues and space to support social distancing), Reflective Motivation (awareness and understanding of risk of transmission), and Social Opportunity (observing others' adhering to guidelines). These findings suggest that the actions of others, environmental supports, and perception of risk have an important role in influencing social distancing behaviour among young people. The COM-B factors identified in this study can inform the development of tailored interventions using models such as the Behaviour Change Wheel. 


\section{Introduction}

In response to the COVID-19 pandemic, social distancing guidelines were introduced in both Northern Ireland (NI) and the Republic of Ireland (RoI) in March 2020 [1] and required fundamental changes in how people interact with each other. Social distancing involves a wide range of strategies designed to minimise the spread of the virus by reducing contact between individuals, involving but not limited to, staying at home; reducing social contacts; and maintaining physical distance during interactions with other people [2,3]. While guidance on whether individuals should remain one or two meters apart differs across countries, the key principle is that individuals limit their contacts and keep a physical distance between themselves and other people during any interaction.

Social distancing has been shown to be an important component of measures designed to reduce the spread and impact of COVID-19. In NI, early distancing measures were estimated to have reduced the $\mathrm{R}$ rate of transmissions from 2.8 to 0.8 [4]. A systematic review of early efforts to control the spread of COVID-19 additionally estimated that physical distancing of over one meter was important in reducing transmission (pooled adjusted OR $0.18,95 \%$ CI 0.09 to $0 \cdot 38$ ) [5]. Furthermore, a review of studies on the effect of social distancing alone on $\mathrm{H} 1 \mathrm{~N} 1$ also found a median reduction rate of $23 \%$ of cases in the general population; combined with other measures this rose to a median reduction of $75 \%$ [6].

While young people (e.g. <25) [7] who are deemed medically healthy may experience comparatively lower risk of serious effects of COVID-19, they play an important role in preventing its spread.

Young people often have large social circles and are at a developmental stage in which social interactions and relationship building are considered important [7]. Young people may be more influenced by their peers, which may make adhering to social distancing regulations difficult should other members of their social groups not comply with guidelines [7]. In NI in June 2020 there were reports of large crowds of young people gathering on beaches and other public places raising concerns that young people were not adhering to social distancing guidelines [8]. Recent research has also indicated specific challenges faced by young people during the pandemic related to isolation, loneliness and anxiety [7,9], which may impact on behaviours related to social distancing. 
Understanding behaviours is key in order to change them. Behaviour change occurs when an individual has the physical and psychological capability to make changes, the motivation to make changes, and the physical and social opportunities to make changes (The COM-B model) [10]. Understanding the interactions between these variables, and what influences them, is important to inform the design of interventions to support social distancing among young people; with the principle that particular behaviours are most likely to occur when capability, opportunity and motivation are present. Furthermore, identifying the mechanisms of action (the COM components) underpinning social distancing behaviour, can inform the systematic selection of intervention functions and allied policy supports, using the Behaviour Change Wheel as a guiding tool $[10,11]$.

Given the importance of social distancing in reducing transmission of COVID-19, this paper explores the psychological, social, and environmental factors which support ('facilitators') or thwart ('barriers') efforts to maintain a distance from others outside the household among young people living in NI or the RoI. The findings reported are based on a survey which was undertaken between July $28^{\text {th }} 2020$ and August $24^{\text {th }} 2020$ [12], as lockdown measures were being eased, and thus reflects on the societal and legislative context during this timeframe.

\section{Methods}

\subsection{Design and participants}

The cross-sectional survey collected anonymous quantitative data (via fixed response scales) and qualitative data (open text questions) remotely via Qualtrics software. The survey was open July $28^{\text {th }}$ 2020 - August $24^{\text {th }} 2020$. The survey closed on August $24^{\text {th }}$ as this marked the start of the process of returning to School/University/College which would introduce different contextual variance, thus impacting the interpretation of results. Ethics approval was obtained through Queen's University Belfast on July $27^{\text {th }} 2020$ and the study is pre-registered on AsPredicted.org (reference: \#45900).

Convenience sampling was used to recruit young people/adults aged 16-25 years living in NI/ROI on social media and via youth organisations, schools, and Higher Education institutions. Participants 
were given the opportunity to enter into a raffle to win a $£ 100$ Amazon voucher for completing the survey. As the primary analysis included frequency statistics (reported in full in Berry et al. [12]) and qualitative analytic methods, we aimed to recruit as many participants as possible to facilitate this analysis. Braun et al. [13] discuss an upper end of 100+ participants to support thematic analysis of online survey responses, and, while this is largely determined by the richness of the data and saturation, we aimed to recruit at least 100 participants.

\subsection{Materials and procedure}

The online survey was developed in collaboration with members of the HSC Research and Development Division Behaviour Change Group [14], and was piloted by a representative group of young people to inform further adaptions to support relevance and understanding [15]. The survey items were guided by the COM-B model [10], to provide a theoretical framework a priori, and were deemed relevant given the applications of the model in relevant contexts [11].

The survey was divided into five sections: 1) COVID-19 knowledge and behaviour 2) social and environmental influences on social distancing 3) Attitudes and emotions about social distancing 4) Exploring views and experiences of social distancing 5) Demographics and COVID-19 exposure. Sections 1-3 and 5 were fixed response questions, which used yes/no or Likert scale answer formats (data reported in Berry et al. [12]). The three open text questions in section 4 included: 1) 'What things make it difficult to stick to the COVID-19 guidelines on social distancing?' 2) 'What things help you to stick to the COVID-19 guidelines on social distancing?' 3) 'What would make it easier to keep a distance when you see your friends or family outside your household?'

Potential participants accessed the survey via a link, which directed them to the information page and a series of consent statements. After providing consent participants were directed to the main survey and were provided with a debrief form upon completing the survey.

\subsection{Analysis}

Descriptive statistics were used to capture the demographic composition of the sample, rates of COVID-19 related exposure, and to explore common barriers to social distancing through frequency 
128 Behaviour Change Group, which presents the descriptive statistics and frequencies across responses in full and can be found online [12].

130 A combined approach to qualitative analysis was adopted to ensure that findings were methodologically sound, while also providing practically and clinically useful results. Reflexive thematic analysis [16,17], framed by a subtle realist approach [18], was used to inductively code and develop subthemes. The qualitative analytic approach was informed by a review undertaken by McGowan and colleagues [19], which recommends that behaviour change theory should be applied flexibly in qualitative work, to ensure that codes and prospective themes are not limited by the framework applied. This enabled the primary qualitative analysts in the team (EB and SA) to inductively code, and develop subthemes liberally from the data. The analysis process followed the key steps outlined by Braun and Clarke [16] which includes transcription and familiarisation with the data, generation of initial codes, examining codes for themes, reviewing potential themes, defining themes, and formulating the report. The data was coded initially by SA and crosschecked by EB. Discussions took place to review codes, which led to the removal, addition, or amalgamation of codes. Parent codes were reviewed and the units of meaning they represented helped to develop subthemes that remained bound to the source code but provided a higher degree of abstraction. This was an iterative process to ensure that the subthemes adequately captured the codes and were valid reflections of the data. Acknowledging the subjective nature of the analytic process, thoughts and observations were noted throughout the analysis and perspectives and interpretations were discussed during team meetings to support a comprehensive reflexive process [20].

The next phase of analysis followed a thematic content analysis approach [21]. This consisted of a deductive mapping process in which the COM-B was used as a thematic framework to organize subthemes extracted. Subthemes extracted were categorised under the COM components of the COMB model, where they were deemed to conceptually fit [19]. Data analysts SA and EB remained observant of subthemes that deviated from the COM-B framework. The COM-B thus provided a framework for overarching themes i.e. following the initial inductive coding and subtheme 
construction themes were assigned deductively. Both data coders are trained qualitative researchers and have a sound understanding of the COM-B model and its applications. EB, SA, and CJ contributed to the interpretation of themes and production of this report. Findings are reported in line with Consolidated criteria for reporting qualitative research guidelines in keeping with best practice (Tong, Sainsbury, \& Craig, 2007) [22].

Deductive mapping of the more focused subthemes to COM components facilitated public health professionals in the identification of intervention functions, policy categories, and behaviour change techniques according to the Behaviour Change Wheel [10]. While the purpose of this study was not to propose explicit intervention strategies, the mapped subthemes provide direction as to which intervention functions and policy supports can facilitate behaviour change in this context.

\section{Results}

A total of 477 young people completed the survey. Of these, $96 \%$ were residents of Northern Ireland and $73 \%$ were female. The average age was 21 years with a standard deviation of $2.4($ range $=9)$. Eighty-one percent of young people were living in their family home at the time of completing the survey; $3 \%$ lived in owned accommodation; $2 \%$ lived in student rented accommodation; and $12 \%$ lived in privately rented accommodation. Most respondents lived in households with 3-5 people (73\%). One in 6 young people reported living with a chronic health condition, 10\% reported having experienced symptoms consistent with COVID-19. Most young people reported that they were not shielding themselves or others in their household (96\% and $81 \%$ respectively). See Berry et al. [12] for further information.

Of the total 477 survey respondents, 352 respondents provided at least one free text response (this subsample did not differ significantly from the total sample across relevant demographic factors). Thematic analysis of the each free text question led to the development of subthemes, which pertained to the perceived 'barriers' and perceived 'facilitators' of social distancing. Perceived facilitators was explored in the context of what is currently helpful to support social distancing and what would 
further help to support social distancing more (the latter is discussed in brief but full list of subthemes and supporting quotes can be found in Table 3). Subthemes extracted inductively are described under the Capability, Opportunity, and Motivation components, to which they have been conceptually mapped.

\subsection{Barriers to social distancing $(\mathrm{Q} 1)$}

Barrier-related subthemes mapped onto all three COM components, with the exception of physical capability (see Table 1).

\section{Psychological capability}

Psychological capability refers to an individual's knowledge and skills to engage in the behaviour, and includes elements of self-regulation [10]. Three subthemes aligned with psychological capability [42 total comments in total]: 1) 'Lack of clear guidance about expected behavior', 2) 'Challenge of regulating behavior', and 3) 'Effect of alcohol on ability to maintain behavior'. The first subtheme relates to the lack of confidence in and understanding of the formal guidelines around social distancing. There was uncertainty about what the instructions to social distance mean in reality, with messages described as "vague" (participant 9), and young people also felt like the messages were contradictory. Moreover, young people reported feeling confused because of the "Changing messages, scattered dissemination of information" (participant 271).

"Working as a key worker with friends, then meeting up with them outside work - it is nigh on impossible to socially distance in work and masks are only just coming in, why would we bother distancing if we go for food after work whenever we have just been closer than distancing in work?" (participant 144)

Regarding subtheme two, young people mentioned that it can be "easy to forget" to keep a distance from others while socialising because it's not a habit (participant 25). This challenge of opposing entrenched social habits extends to the normative social behaviour people engage in while in the presence of others such as hugging others and shaking hands. 

shop where someone is also looking at the same item" (participant 352)

207

Subtheme three overlaps with subtheme two, capturing young people's thoughts around alcohol consumption. Some young people felt that alcohol makes it more likely that people will revert to old habits and forget to distance.

"When people simply disregard the rules and get close to you. Alcohol also makes it difficult to stick to social distancing due to the loss of awareness." (participant 198)

\section{Social opportunity}

Social opportunity refers to the impact of an individual's social and cultural 'milieu' on behaviour [10]. One subtheme extracted aligned with social opportunity: 'Actions of others' as a disincentive' [147 comments]. This was the most frequently reported barrier to social distancing and relates to observing other people not keeping their distance from others in public spaces. Being physically around other people who are not following the distancing rules makes it hard for young people to feel compelled to practice social distancing themselves. Seeing friends or other young people not keeping distance from others on social media is also discouraging as it implies that none of their peers are doing it.

"Pubs and restaurants not providing distancing at tables - have only met up with two friends since March, once for a walk and once to chat at a distance in a garden, and I left when the others went inside. Also, Instagram: everyone is posting pictures of themselves all over their friends at parties etc. and it's so prevalent it sometimes makes me wonder if I've just imagined the whole pandemic? Why do I stick so strongly to the guidelines when nobody else I know seems to?" (participant 118)

\section{Physical opportunity}

Physical opportunity refers to an individual's surroundings and physical resources that influence behaviour [10]. One subtheme extracted aligned with physical opportunity [103 comments in total]: 'Lack of environmental support for social distancing'. Many young people mentioned aspects of their 
physical environment that make it harder to distance. In particular, young people find it hard to keep a distance in small or busy spaces such as retail environments, friends' homes, and workplaces.

"Small spaces in shops, corridors, work, friends houses etc... it isn’t always possible to effectively socially distance in certain places. Some people are also not very considerate of your own space" (participant 161)

Some young people also mentioned having to car share as an unavoidable barrier to keeping distance.

"Most of my friends don’t drive so they have to get into my car" (participant 83)

\section{Automatic motivation}

Automatic motivation refers to feelings, habits, and 'innate dispositions' that affect behaviour [10].

One subtheme extracted was categorized as automatic motivation [71 comments in total]: 'Absence of physical affection and contact'. The motivation to keep a distance from others was diminished due to young people missing physical affection and contact from friends and family. Young people missed being with friends/loved ones in-person and expressed feeling lonely because of the lack of in-person contact.
"I live in a rural area, and I was the loneliest I have ever been during lockdown. I was almost desperate to get back to Belfast to see my friends and boyfriend, who I hadnt seen in four months." (participant 315)

\section{Reflective motivation}

Reflective motivation refers to the range of more conscious processes such as planning, making evaluations and risk perception [10]. Two subthemes extracted aligned with reflective motivation [21 total comments in total]: 1) 'Difficulty accepting the pandemic' and 2) 'Sense of low risk of transmission/contraction'. With respect to the first subtheme, young people reported that keeping distance can feel unnatural and strange, which influences their motivation to social distance. 
"The pandemic being a new, unfamiliar situation in strange circumstances, causing it to feel unnatural to have to stay away from my friends etc., as I am used to closer contact with them hugs, etc.” (participant 322)

Regarding the second subtheme, a smaller group of young people found it difficult to perceive the risk of not social distancing for reasons including disbelief of the infectiousness and seriousness of COVID-19 and feeling that measures taken such as forming a social "bubble of people to chat" meant they did not have to distance from friends (participant 344).

"The fact that none of my friends or I have ever caught it despite not social distancing. Can be hard to appreciate its importance" (participant 220)

\subsection{Facilitating social distancing (Q2: existing supports)}

Subthemes related to facilitators to social distancing behaviour were mapped onto all three COM components, with the exception of physical capability (see Table 2).

\section{Psychological capability}

Two subthemes aligned with Psychological capability [42 total comments in total]: 1) 'Clear and consistent guidelines' and 2) 'Adapting (pre-pandemic) lifestyle behavior'. Relating to the first subtheme, young people felt that keeping a distance from others in social settings is easier when public spaces like shops have clear instructions about how people are expected to behave and when there is "Consistent guidance from the government on the news and social media" (participant 52). Thus, clarity of instructions was important at a lower, rudimentary level e.g. shopping behaviour, however, there was also the sense that coherent messages from authorities was also important.

"Clearer views and instructions from the government as the people I know have varied knowledge of what's the most up to date information." (participant 284)

Some young people reported that adjusting their daily lifestyle by, for instance, "staying at home as much as possible" (participant 287) and only going out when necessary helps them to keep distance 
by avoiding situations where they need to ensure that they keep a distance from others. A small number of young people also mentioned that adjusting forms of communication with family and friends, for example talking to "friends through social media" and changing the setting of social meetings by "meeting up with friends in quiet parks" (participant 233) helps them to avoid close contact.

\section{Social opportunity}

One subtheme extracted aligned with social opportunity [55 comments in total]: 'Actions of others as an incentive'. Many young people noted that it is easier to keep distance when others also keep distance, and it was felt that others supporting this behaviour by "acting as good role models" (participant 66) encouraged them to practice social distancing. The message underpinning this subtheme compliments the social opportunity barrier previously acknowledged.

"Seeing others distancing make me distance" (participant 124)

\section{Physical opportunity}

One broad subtheme extracted aligned with physical opportunity [146 comments in total]:

'Environmental support for social distancing: cues and space'. This subtheme suggests that physical environment has a large impact on young people's perceived ability to keep distance and their capacity to remember to keep distance. One element of this subtheme related to how young people felt that environmental cues and reminders and physical prompts facilitated their ability to keep a distance from others and reminded them to keep a distance from others.

"Stickers on the ground, spaced out tables when eating, reminders on social media/billboards etc" (participant 155)

Another aspect of this subtheme related to the need to have adequate space to practice social distancing, which suggested that young people felt that keeping a distance from others is easier when the physical environment aids this, for example by restructuring indoor spaces or meeting others in outdoor settings. 
Automatic motivation

One subtheme extracted aligned with automatic motivation [22 comments in total]: 'Enforcement and perceived repercussions'. A number of young people also mentioned that they keep distance when they are made to. This primarily related to circumstances when (shop/other) staff enforce it or "implementing laws" (participant 168), in which case the risk of punishment is visible.

"when there are strict rules in shops/ businesses that easily instruct you what to do before entering. However I only actually do it if there is a member of staff at the door reminding everyone to use the soap dispenser." (participant 321)

\section{Reflective motivation}

One subtheme extracted aligned with reflective motivation [95 comments in total]: 'Awareness of risk of transmission'. Young people frequently mentioned an awareness of risk as a motivation to keep a distance from other in social situations. They reported feeling motivated by a drive to keep themselves or others safe, to avoid deaths and "helping stop the spread" (participant 92). Some said they kept distance because it was "the right thing to do from the news" (participant 228), which may relate to a number of factors including news reports of contagion and death rates, as well as news coverage on government guidelines around social distancing behavior.

"Knowing I'm less likely to make myself/others sick" (participant 64)

A small group of young people also reported feeling more motivated to keep a distance from others in social situations after "Noticing that daily cases of covid are increasing" in their own "council area" (participant 251).

\subsection{Facilitating social distancing (Q3: further supports needed)}

The final question asked respondents what could be improved or put in place to further facilitate social distancing behaviour. Subthemes for this question were mapped onto all three COM 
components, with the exception of physical capability and automatic motivation (see Table 3).

331 Subthemes largely complimented the subthemes identified for current/existing facilitators, with regard to greater clarity of guidelines in different social circumstances, increased environmental supports, increased visibility of the supportive behaviour of others, the need for more enforcement of 'rules', and the importance of knowing the risks of contagion and contraction.

However, one subtheme, which aligned with reflective motivation, conveyed a different perspective to any of the subthemes described previously [71 comments in total]: 'Sense that nothing (more) can help'. The comments that led to the development of this subtheme tended to relate to the perspective that there is "nothing that can make it [social distancing] easier" and that distancing from others was "common sense" (participant 183), or indicated an uncertainty about what can further help or the sense that nothing can help.

"Nothing. To be honest I have no ideas on how it could be made easier." (participant 317).

Table 1: Barrier themes clustered under COM-B components and supporting quotes (Q1)

\begin{tabular}{|c|c|c|}
\hline COM-B component & Subtheme & Sample quote \\
\hline Psychological capability & $\begin{array}{l}\text { Lack of clear guidance about } \\
\text { expected behavior } \\
\text { Challenge of regulating behavior } \\
\text { Effect of alcohol on ability to } \\
\text { maintain behavior }\end{array}$ & $\begin{array}{l}\text { "Vague statements about distancing } \\
\text { because people can interpret it in different } \\
\text { ways" (participant 9) } \\
\text { "It's just culture that you hug people when } \\
\text { you see them so sometimes you get caught } \\
\text { up you forget." (participant 199) } \\
\text { "It's difficult when others don't do it or } \\
\text { when any alcohol is consumed." } \\
\text { (participant 185) }\end{array}$ \\
\hline
\end{tabular}




\begin{tabular}{|c|c|c|}
\hline Physical capability & - & - \\
\hline Social opportunity & $\begin{array}{l}\text { Actions of others as a } \\
\text { disincentive }\end{array}$ & $\begin{array}{l}\text { "People ignore the regulations and } \\
\text { guidance. So if someone passes close to me } \\
\text { then it defeats the purpose of me doing it if } \\
\text { very few are watching their distance } \\
\text { around everyone." (participant 235) }\end{array}$ \\
\hline Physical opportunity & $\begin{array}{l}\text { Lack of environmental support } \\
\text { for social distancing }\end{array}$ & $\begin{array}{l}\text { "Too many people in shops, too many } \\
\text { people in general, not knowing what way } \\
\text { to go in a shop" (participant 202) }\end{array}$ \\
\hline Automatic motivation & $\begin{array}{l}\text { Absence of physical affection } \\
\text { and contact }\end{array}$ & $\begin{array}{l}\text { "Seeing your friends and family after so } \\
\text { long and not being able to hug" } \\
\text { (participant 26) }\end{array}$ \\
\hline Reflective motivation & $\begin{array}{l}\text { Difficulty accepting the } \\
\text { pandemic } \\
\text { Sense of low risk of transmission } \\
\text { or contraction }\end{array}$ & $\begin{array}{l}\text { "My family, friends, partner. Also, the fact } \\
\text { i am sick of hearing the social distancing } \\
\text { radio adverts constantly like propaganda. } \\
\text { For me, the more i hear it, the less i listen." } \\
\text { (participant 307) } \\
\text { "I want to be close to people I care about, } \\
\text { to hug them, it's hard if other people don't } \\
\text { as it feels pointless especially when } \\
\text { transmission is very low" (participant 77) }\end{array}$ \\
\hline
\end{tabular}

345 Table 2: Facilitator (existing supports) subthemes clustered under COM-B components and 346 supporting quotes $(\mathrm{Q} 2)$

\begin{tabular}{|l|l|l|}
\hline COM-B component & Subthemes & Sample quote \\
\hline
\end{tabular}




\begin{tabular}{|c|c|c|}
\hline Psychological capability & $\begin{array}{l}\text { Clarity and consistency of } \\
\text { guidelines and instructions } \\
\text { Adapting (normal) lifestyle } \\
\text { behavior (include adapting } \\
\text { usual forms of communication) }\end{array}$ & $\begin{array}{l}\text { "Restrictions on everybody, clear } \\
\text { and visible instructions" (participant } \\
326 \text { ) } \\
\text { "Limiting how much time I actually } \\
\text { spend with people outside my } \\
\text { household. The more time you } \\
\text { spend with people it's easy to } \\
\text { become used to it and forget about } \\
\text { distancing" (participant 268) }\end{array}$ \\
\hline Physical capability & - & - \\
\hline Social opportunity & $\begin{array}{l}\text { Actions of others as an } \\
\text { incentive }\end{array}$ & $\begin{array}{l}\text { "Having friends that are strict as } \\
\text { well. If majority of people don't, it } \\
\text { makes you feel self conscious" } \\
\text { (participant 15) }\end{array}$ \\
\hline Physical opportunity & $\begin{array}{l}\text { Environmental support for } \\
\text { social distancing: cues and } \\
\text { space }\end{array}$ & $\begin{array}{l}\text { "Rules in shops, tape on floors etc. } \\
\text { that give me guides on where I } \\
\text { should be standing." (participant } \\
\text { 159) }\end{array}$ \\
\hline Automatic motivation & $\begin{array}{l}\text { Enforcement and perceived } \\
\text { repercussions of not social } \\
\text { distancing }\end{array}$ & $\begin{array}{l}\text { "If it's a legal requirement" } \\
\text { (participant 1) }\end{array}$ \\
\hline Reflective motivation & $\begin{array}{l}\text { Awareness of risk of } \\
\text { transmission }\end{array}$ & $\begin{array}{l}\text { "The knowledge that it is the right } \\
\text { thing to do to keep people safe." } \\
\text { (participant 349) }\end{array}$ \\
\hline
\end{tabular}


Table 3: Facilitator (additional supports needed) subthemes clustered under COM-B components and supporting quotes $(\mathrm{Q} 3)$

\begin{tabular}{|c|c|c|}
\hline COM-B component & Subthemes & Sample quote \\
\hline Psychological capability & $\begin{array}{l}\text { Clear and consistent guidelines } \\
\text { Adjusting lifestyle and social } \\
\text { activities }\end{array}$ & $\begin{array}{l}\text { "Clearer guidelines. There are too } \\
\text { many contradictions about!" } \\
\text { (participant } 177 \text { ) }\end{array}$ \\
\hline Physical capability & $\begin{array}{l}\text { Environmental supports to } \\
\text { facilitate and encourage } \\
\text { behaviour }\end{array}$ & $\begin{array}{l}\text { "Perspex glass divisions in indoor } \\
\text { spaces, areas marked with tape } \\
\text { outside, maybe a technological } \\
\text { reminder that youre standing too } \\
\text { close to someone? Like an app" } \\
\text { (participant } 305 \text { ) }\end{array}$ \\
\hline Social opportunity & $\begin{array}{l}\text { Supportive beliefs and values of } \\
\text { others }\end{array}$ & $\begin{array}{l}\text { "If everyone had the same goal in } \\
\text { mind. Lots of people don't believe } \\
\text { in the virus or in the prevention } \\
\text { measures" (participant 130) }\end{array}$ \\
\hline Physical opportunity & - & - \\
\hline Automatic motivation & - & - \\
\hline Reflective motivation & $\begin{array}{l}\text { Enforcement of rules with } \\
\text { repercussions } \\
\text { Increasing awareness of the } \\
\text { benefits versus risks }\end{array}$ & $\begin{array}{l}\text { "More clear or strict guidelines, if it } \\
\text { is necessary. If everyone is forced to } \\
\text { do it, then it would be easier." } \\
\text { (participant 139) } \\
\text { "More public understanding of the } \\
\text { severity of coronavirus. Most people } \\
\text { are bored of it now and seem to act } \\
\text { like it doesn't exist anymore." } \\
\text { (participant 158) }\end{array}$ \\
\hline
\end{tabular}




\begin{tabular}{|l|l|l|}
\hline & $\begin{array}{l}\text { Sense that nothing (more) can } \\
\text { help }\end{array}$ & $\begin{array}{l}\text { "Nothing it's always going to be } \\
\text { hard" (participant 68) }\end{array}$ \\
\hline
\end{tabular}

\section{Discussion}

354 This study explores the commonly experienced barriers to and facilitators of social distancing behaviour in young people predominantly from Northern Ireland, using the COM-B model to organize and make sense of the data. This study focuses on a sample of young people, primarily students, who recognize the supports needed to endorse social distancing behaviour, but who experience a range of factors which impede the extent to which they implement this behaviour in daily life. As reported in Berry et al. [12], while a large number of young people social distance frequently, a substantial proportion reported that they do not. This is consistent with previous evidence indicating that adherence to social distancing guidelines is generally lower in younger populations [23,24]. The frequency data reported in Berry et al. [12] suggests that actions of peers, forgetting to keep a distance from others, environmental constraints, and unhelpful emotions contribute to intentions to, or perceived ability to social distance (see Berry et al. [12]). Qualitative analysis of free-text survey responses provided the scope to further explore these observed frequencies.

A large number of responses in relation to the barriers and facilitators of social distancing revolved around physical opportunity, and more specifically, the importance of context, cues, and prompts in helping young people to social distance. This is an important area to consider when designing interventions to prompt behaviour and can be particularly effective when combined with clear and simple guidance. Social distancing behavior among young people is influenced by the structure and organization of businesses. For example, pubs, restaurants, and shops not accommodating and/or not enforcing social distancing guidelines was a commonly reported factor among young people. 
374 Correspondingly, visual cues and reminders, guidance from staff, and premises following guidelines were consistently highlighted as enablers for social distancing.

376 Observing the actions of peers/others not distancing was also a commonly raised challenge for young 377 people. Additionally, seeing friends/others posting photos on social media in which social distancing was absent was another important barrier to social distancing which specific messaging and normative interventions could target. Moreover, the requirement to maintain physical distance from friends, partners, and family, and the emotional difficulties this caused, further contributed to the wider social challenges experienced by young people. Certainly, evidence demonstrates the negative psychological impact of continued isolation for young people in particular [25,26]. It is essential that future interventions and public health campaigns for young people appreciate this reality and utilize strategies to help young people navigate these challenging psychological and social dynamics. A number of young people indicated that they found it difficult to accept the 'reality' of the pandemic, which, since the first lockdown ensued has resulted in drastic change to day-to-day life. It is notable that there was an absence of reported feeling of invincibility to engage in life as they would have preCOVID-19. With this in mind, it is understandable why some young people find it more difficult to follow guidelines on social distancing if they are less able to accept the lifestyle changes and sacrifices advised. For the most part, however, many young people reported feeling worried about catching the virus or transmitting it to others and, in fact, this increased awareness of risk was a commonly suggested enabling factor for social distancing in young people.

This study captures the experiences and perspectives of young people living in NI/ROI during an unforeseen and unfamiliar societal trauma. The survey aimed to capture the factors which thwart or support social distancing, however the content of themes highlight the wider psychosocial challenges experienced by this group, such as the absence of physical affection and feeling jaded by social structures. The results bare relevance for the ongoing challenge of maintaining physical distance, particularly as lockdown restrictions ease. Using the Behaviour Change Wheel as an extended 
through a series of intervention functions and policy supports, which evidence suggests can support behaviour change.

402 The findings of this paper strongly indicate that interventions intended to encourage social distancing must go beyond informing young people about the need to social distance (of which they demonstrate high levels of understanding already) but must focus on social, emotional, and environmental enablers and barriers. It's important to note that changing behaviour is not just about 'delivering the message' to young people to try to convince them to do the right thing. Nor can we assume that young people are less invested or interested in public health advice. Public health practitioners will be more successful in influencing the actions of young people if they address the unique barriers identified for this important demographic group, adopting a holistic approach, which acknowledges the range behavioural influences and considers the unique challenges that COVID-19 poses for young people.

This requires having empathy for young people and ensuring that their needs and concerns are at the heart of the design of any intervention strategy. Otherwise, engagement is likely to be low or shortlived. Local and international reports affirm the need to capture to voices of young people to help shape governmental decisions and policy to support engagement and also mitigate the long-term impact of COVID-19 for the younger generation, who are likely to be more harshly affected by the psychosocial and economic repercussions of prolonged periods of lockdown $[27,9]$.

It is important that the efforts made by young people are not undervalued and that incidents of young people not adhering to guidelines are not sensationalized by the media (e.g. scenes of young people gathering in public spaces, house parties), which, as conveyed by the 'social opportunity' theme, inadvertently reinforces the undesirable behaviour. In other words, the more that young people are provided with these less helpful role models, the less incentivized they will be to engage in social distancing $[28,29]$. There is also a need to rebuild or maintain trust in civil society organizations, which may have decreased for young people (among other demographic groups) as result of unclear decisions, conflicting messages, and frustration [27]. 
This study was conducted during the graduated easing of the first lockdown during the summer of 2020 and thus is reflective of the thoughts, feelings, and behaviours which occurred in this context. Behaviour is likely to evolve throughout the pandemic. The findings from this study should be seen as indicative of important trends, but further research to validate the findings would be useful. Further qualitative research would be additionally useful in deepening understanding of the themes presented within this study, since the survey format limited the extent to which responses could be expanded upon. This cross-sectional study also restricts the findings to a single snapshot of social distancing perceptions and behaviours at the time data was collected. Longitudinal work would provide the data to examine change in perceptions and behaviour overtime, which is valuable to measure the stability of these variables.

Moreover, respondents from the survey were almost exclusively from Northern Ireland. Even though many findings may be similar for young people in the Republic of Ireland, generalizing such findings should be treated with caution. Information on ethnicity was also not collected. Given the disproportionate impact of COVID-19 on BAME communities [30,31], further research within cohorts of young people from minority ethnic groups is important. The average age of participants was 21 years old, so our study provides limited insight into the experiences of younger participants aged between 16-18 years old. And only $27 \%$ of respondents were male, again highlighting a group towards which future research may be targeted. Other research has indicated that social distancing adherence is lower in men [24], further indicating the importance of understanding responses and behaviours among younger men.

This study provides a novel glimpse of the determinants of social distancing among young people living in NI/ROI, providing information relevant for the design of targeted public health interventions using frameworks such as the Behaviour Change Wheel [10]. As lockdown measures are eased, it is important to understand current social distancing behaviours and intentions to maintain these where 
necessary in the longer-term, especially as the nature of the pandemic is inherently unpredictable and the emergence of new variants a potential risk on the horizon. Moreover, with the vaccine rollout, it is possible that perception of risk may decrease, thus influencing transmission-preventative behaviour. While vaccine behaviour in itself is an important public health matter, we also need to consider how receipt of the vaccine impacts willingness to maintain social distancing recommendations as we progress through 2021 and beyond. Given the pace of social change during the course of the pandemic, regular research should be conducted on how young people's behaviors are changing in response to different social distancing requirements and legislative changes.

\section{Acknowledgements}

We would like to thank young people in Northern Ireland/Republic of Ireland for taking time to provide their views and experiences on this important topic. We would also like to acknowledge the support of the wider HSC Research and Development Division Behaviour Change Group with the planning and dissemination of this study (members as follows: Nicola Armstrong, Janice Bailie, Sarah Allen, Diane Anderson, Stephen Bergin, Emma Berry, Declan Bradley, Gavin Breslin, Karen Casson, Mary Dallat, Martin Dempster, Laura Dunne, Diana Gossrau-Breen, Frank Kee, Sarah Miller, Gary Maxwell, Maurice Mulvenna, Helen McAneney, Margaret McCrory, Diarmuid O’Donovan, Colette Rogers, Gillian Shorter, Danielle Sinclair, Rachael Singleton, Fiona Teague, Mark Tully, Stephen Wilson, and Anita Yakkundi).

\section{References}

[1] Mahase E. Covid-19: UK starts social distancing after new model points to 260000 potential deaths. BMJ. 2002;325(7357):184.

[2] Public Health England [internet]. Guidance on social distancing for everyone in the UK. United Kingdom: PHE, c2020 [cited June 2021]. Available from: 
https://www.gov.uk/government/publications/covid-19-guidance-on-social-distancing-and-for-

478 vulnerable-people/guidance-on-social-distancing-for-everyone-in-the-uk-and-protecting-older-people-

and-vulnerable-adults

480 [3] Centers for Disease Control and Prevention [internet]. Guidance for unvaccinated people Social

481 Distancing Keep a Safe Distance to Slow the Spread. United Kingdom: CDC, c2020 [cited June 2021]. Available from: https://www.cdc.gov/coronavirus/2019-ncov/prevent-getting-sick/socialdistancing.html

484

485

486

487

[4] Department of Health [internet]. Modelling data shows social distancing works. Northern Ireland: DoH, c2020 [cited June 2021]. Available from: https://www.health-ni.gov.uk/news/modelling-data$\underline{\text { shows-social-distancing-works }}$

[5] Chu DK, Akl EA, Duda S, Solo K, Yaacoub S, Schünemann HJ, El-harakeh A, Bognanni A, Lotfi T, Loeb M, Hajizadeh A. Physical distancing, face masks, and eye protection to prevent person-toperson transmission of SARS-CoV-2 and COVID-19: a systematic review and meta-analysis. The lancet. 2020 Jun 27;395(10242):1973-87.

[6] Ahmed F, Zviedrite N, Uzicanin A. Effectiveness of workplace social distancing measures in reducing influenza transmission: a systematic review. BMC public health. 2018 Dec;18(1):1-3.

[7] Orben A, Tomova L, Blakemore SJ. The effects of social deprivation on adolescent development and mental health. The Lancet Child \& Adolescent Health. 2020 Aug 1;4(8):634-40.

[8] Hallday G [internet]. Coronavirus: Call for travel restrictions to halt scenes like this as young people in Northern Ireland urged 'act responsibly' during lockdown. Northern Ireland: Belfast Telegraph, c2020 [cited June 2021]. Available from: https://www.belfasttelegraph.co.uk/news/health/coronavirus/coronavirus-call-for-travel-restrictionsto-halt-scenes-like-this-as-young-people-in-northern-ireland-urged-act-responsibly-during-lockdown$\underline{39255476 . h t m l}$ 
502 Summer Report. Northern Ireland: NIYF, c2020 [cited June 2021]. Available from:

504 [10] Michie S, Van Stralen MM, West R. The behaviour change wheel: a new method for 505 characterising and designing behaviour change interventions. Implementation science. 2011 506 Dec;6(1):1-2.

[11] West R, Michie S, Rubin GJ, Amlôt R. Applying principles of behaviour change to reduce SARS-CoV-2 transmission. Nature human behaviour. 2020 May;4(5):451-9.

[12] Berry E, Bradley D, Tully MA, Allen S, Mulvenna M, Dempster M, Shorter G, \& McAneney H, on behalf of the Public Health Agency Behaviour Change Group. Exploring the facilitators and barriers to following COVID-19 guidelines on social distancing among young people in Northern Ireland and Republic of Ireland Report No: 2. Belfast: Public Health Agency. Available from: https://research.hscni.net/sites/default/files/BCG\%20Report\%202_07.10.2020.pdf

[13] Braun V, Clarke V, Boulton E, Davey L, McEvoy C. The online survey as a qualitative research tool. International Journal of Social Research Methodology. 2020 Aug 16:1-4.

[14] Berry E [internet]. The Behaviour Change Group: supporting transmission prevention behaviour in Northern Ireland. Belfast: Public Health Agency, c2020 [cited June 2021]. Available from: https://www.publichealth.hscni.net/node/5367 publishing ltd. London. 2016 Mar 24:359-81.

[16] Braun V, Clarke V. Using thematic analysis in psychology. Qualitative research in psychology. 2006 Jan 1;3(2):77-101. 
designs: Quantitative, qualitative, neuropsychological, and biological. American Psychological Association; 2012. p. 57-71.

[18] Mays N, Pope C. Assessing quality in qualitative research. Bmj. 2000 Jan 1;320(7226):50-2.

[19] McGowan LJ, Powell R, French DP. How can use of the Theoretical Domains Framework be optimized in qualitative research? A rapid systematic review. British Journal of Health Psychology. 2020 Sep;25(3):677-94.

[20] Elo S, Kääriäinen M, Kanste O, Pölkki T, Utriainen K, Kyngäs H. Qualitative content analysis: A focus on trustworthiness. SAGE open. 2014 Feb 5;4(1):2158244014522633.

[21] Miles MB, Huberman AM. Qualitative data analysis: An expanded sourcebook. sage; 1994 Jan 12.

[22] Tong A, Sainsbury P, Craig J. Consolidated criteria for reporting qualitative research (COREQ): a 32-item checklist for interviews and focus groups. International journal for quality in health care. 2007 Dec 1;19(6):349-57.

[23] Atchison C, Bowman LR, Vrinten C, Redd R, Pristerà P, Eaton J, Ward H. Early perceptions and behavioural responses during the COVID-19 pandemic: a cross-sectional survey of UK adults. BMJ open. 2021 Jan 1;11(1):e043577.

[24] Durand H, Bacon SL, Byrne M, Farrell K, Kenny E, Lavoie KL, McGuire BE, McSharry J, Meade O, Mooney R, Noone C. Adherence to physical distancing guidance in Ireland: a nationally representative analysis from the International COVID-19 Awareness and Responses Evaluation (iCARE) study. HRB Open Research. 2021 Apr 19;4(36):36.

[25] Lee CM, Cadigan JM, Rhew IC. Increases in loneliness among young adults during the COVID19 pandemic and association with increases in mental health problems. Journal of Adolescent Health. 2020 Nov 1;67(5):714-7.

[26] Loades ME, Chatburn E, Higson-Sweeney N, Reynolds S, Shafran R, Brigden A, Linney C, McManus MN, Borwick C, Crawley E. Rapid systematic review: the impact of social isolation and 

loneliness on the mental health of children and adolescents in the context of COVID-19. Journal of

551 the American Academy of Child \& Adolescent Psychiatry. 2020 Nov 1;59(11):1218-39.

552 [27] Allam M, Ader M, Igrioglu G. Youth and COVID-19: Response, recovery and resilience. Paris:

553 Organisation for Economic Co-operation and Development, c2020 [cited in June 2021]. Retrieved

554 from: https://read.oecd-ilibrary.org/view/?ref=134 134356-ud5kox3g26\&title=Youth-and-COVID-

555 19-Response-Recovery-and-Resilience\&_ga=2.1982197.571802095.1625082185-

$556 \quad \underline{1978122031.1618565226}$

557 [28] Andrews JL, Foulkes L, Blakemore SJ. Peer influence in adolescence: Public-health implications for COVID-19. Trends in Cognitive Sciences. 2020 Aug 1;24(8):585-7.

559 [29] Bonell C, Michie S, Reicher S, West R, Bear L, Yardley L, Curtis V, Amlôt R, Rubin GJ.

560 Harnessing behavioural science in public health campaigns to maintain 'social distancing'in response

561 to the COVID-19 pandemic: key principles. J Epidemiol Community Health. 2020 Aug 1;74(8):617-

5629.

563 [30] Mamluk L, Jones T. The impact of COVID-19 on black, Asian and minority ethnic communities.

564 National Institute for Health Research (NHR) report. 2020 May;20(05).

565 [31] Phiri P, Delanerolle G, Al-Sudani A, Rathod S. COVID-19 and black, Asian, and minority ethnic 566 communities: a complex relationship without just cause. JMIR public health and surveillance. 2021

$567 \quad$ Feb 1;7(2):e22581. 